\title{
Students Estimating Large Quantities: From Simple Strategies to the Population Density Model
}

\author{
Lluís Albarracín ${ }^{1 *}$, Núria Gorgorió ${ }^{2}$ \\ ${ }^{1}$ Serra Húnter Fellow, Universitat Autònoma de Barcelona, SPAIN \\ 2 Universitat Autònoma de Barcelona, SPAIN
}

Received 17 January 2017 - Revised 6 May 2018 - Accepted 12 May 2018

\begin{abstract}
We study how a group of 16-year-old students solve a sequence of problems that require estimating large quantities. The problem sequence was designed to foster students creating mathematical models. We characterise the models constructed by the students while working both individually and in small teams and analyse how they evolve throughout the sequence because of having to deal with the restrictions imposed by the real-life context of the different problems. We observe that: a) the students progressively abandon the poorest strategies of the initial individual schemes to embrace strategies adaptable to a greater number of scenarios; $b$ ) students change the conceptual strategies that support their models, not as a result of a conceptual discussion, but as a consequence of a procedural obstacle or limitation; c) they adjust their models by introducing nuances, because of a better mathematization of the given situation. As a group, they finally reach a model - a generalization of the idea of population density - that is not only useful for solving a particular problem, but can apply to other situations.
\end{abstract}

Keywords: models, modelling-eliciting activities, estimation, population density, compulsory secondary education

\section{INTRODUCTION}

When designing classroom activities, a dilemma often arises. The choice must be made between presenting closed activities to students, which promote specific learning that the teacher can direct and control, or open situations, with a higher cognitive demand, in which students build their own knowledge, connecting new ideas with what they have learned before. Focusing on the development of mathematical modelling competence, open-ended activities allow students to explore the nature of real phenomena and create effective mathematical representations that allow them to understand reality, thus reflecting the nature of mathematical thinking. However, it is difficult to anticipate the mathematical content and strategies that students will set in motion to create their own mathematical models. In this work we address this difficulty, by studying the ways in which students solve a sequence of activities that requires estimating the number of objects on a given surface.

We had already characterized the action plans that students devised to solve these kind of situations (Albarracín \& Gorgorió, 2014) and we also knew that problems that are mathematically equivalent but that have different context-specific wording in their formulation resulted in the use of differing models (Albarracín \& Gorgorió, 2013). We had so far shown that almost half of the students in our study were able to create schemes that included mathematical strategies that could actually be applied to solve the problems. Based on the assumption that the number of succeeding strategies would have increased if the students had been allowed to actually implement their plans while working in groups, we wanted to explore a new research avenue. We wanted to study how a class of students aged 16 worked, how they developed their plans towards solving a sequence of activities linked to a Fermi problem that required estimating the number of objects on a given surface. To this end, we designed a modelling sequence (Ärlebäck \& Doerr, 2015a) that was intended to promote a progressive construction of the concepts and processes. The lessons started with the students devising a plan to solve problems individually, then continued to

(C) 2018 by the authors; licensee Modestum Ltd., UK. This article is an open access article distributed under the terms and conditions of the Creative Commons Attribution License (http://creativecommons.org/licenses/by/4.0/). $\square$ Iluis.albarracin@uab.cat (*Correspondence) $\square$ nuria.gorgorio@uab.cat 


\section{Contribution of this paper to the literature}

- Sequences of modelling activities can be constructed by recurrently posing a given problem using different context-specific wording; they are good educational tools to introduce modelling and can generate other learning outcomes also.

- The strategies students constructed/used when solving a sequence of problems that required them to estimate the number of elements on a surface were based on three concepts that support three different models - grid distribution, population density and iteration of a reference point. When working in group, the students progressively adopted conceptually richer strategies, finally opting for the population density model. Sharing the models developed to solve the first problem, their weaknesses and potentialities, was key in how the students linked the resolutions of the other problems in the sequence.

- Facing mathematical modelling for the first time through a sequence of modelling activities, the students connected and coordinated models, but we have no evidence that the students fully integrated the models. Along the sequence, the students did not concatenate modelling cycles, initiating a new cycle for each problem, but adopted or persisted on the model they considered most appropriate among those discussed.

- Students adapted the models to each situation, either shifting strategies or adjusting the procedures. Students shifted models when the strategies that define them involved procedures that could not be activated. Students' discussions were not concerned with the concepts underlying their strategies, not even when they decided to shift models. Students adjusted the models incorporating nuances resulting from a more sophisticated interpretation of the situation they were modelling.

share and discuss the individual plans while working in small groups, in order to finally come to a consensus on "the best way" to solve them.

We characterised the models constructed by the students along the sequence, and we observed how they evolved because of having to deal with the restrictions imposed by the real-life context of the different problems. Focussing on the solving processes of the whole sequence, we observed that: a) the students progressively abandoned the poorest strategies of the initial individual schemes to embrace richer strategies adaptable to a greater number of scenarios; b) students changed the conceptual strategies that support their models not as a result of a conceptual discussion, but as a consequence of a procedural obstacle or limitation; c) they adjusted their models by introducing nuances, because of a better mathematization of the given situation; and d) discussing the models created for the first problem, their weaknesses and potentialities, was key in how they linked the resolutions of the other problems. As a group, they finally reached a model - a generalization of the idea of population density - that was not only useful for solving a particular problem, but could apply to other situations.

Our results show that the models that students developed when faced with mathematically equivalent problems posed in different contexts converged towards the population density model. In this way, we understand that our study opens a possibility of designing modelling sequences that encourage students to construct mathematical models considered relevant from the point of view of the school curriculum, while developing skills that are characteristic of modelling.

\section{CONCEPTUAL FRAME}

\section{On Models and Mathematical Modelling}

The moment students attempt to solve a mathematical problem formulated within a real-life situation, they embark on a mathematization process that may involve abilities and solving strategies related to mathematical modelling. To determine the concept of mathematical model, we chose Lesh and Harel's (2003) perspective:

Models are conceptual systems that generally tend to be expressed using a variety of interacting representational media, which may involve written symbols, spoken language, computer-based graphics, paper-based diagrams or graphs, or experience-based metaphors. Their purposes are to construct, describe or explain other system(s).

Models include both: (a) a conceptual system for describing or explaining the relevant mathematical objects, relations, actions, patterns, and regularities that are attributed to the problem-solving situation; and (b) accompanying procedures for generating useful constructions, manipulations, or predictions for achieving clearly recognized goals. (p. 159) 
A mathematical model will comprise different elements that define it, such as mathematical concepts, symbolic representations of reality, or diagrams and schemes. In addition, a mathematical model will include procedures related to its implementation and use, given that models cannot be exclusively reduced to the conceptual field. From this, we understand that a mathematical modelling activity is one in which students develop and/or use mathematical models.

Students create models to solve problems through complex processes which are still a matter of discussion, on which different opinions currently exist (Borromeo Ferri, 2006). In general terms, it is widely accepted that modelling processes are cyclic in nature (Blum \& Leiss, 2007). In this way, when trying to solve a problem, students will go through a process of different stages and come back to the starting point in an attempt to find a mathematical representation that describes the studied phenomenon or answers the questions in the most suitable way. When trying to validate their model, students will have to decide whether it actually fits their needs. In the case it may not be suitable, they will restart the process with the aim of refining it or creating a different one.

The stages of the modelling process have been analysed by several researchers and a great number of documents have been written on their characterisation (Perrenet \& Zwaneveld, 2012). Pollak (1979) introduced the distinction between the mathematical world and the rest of the world for the study of problems with real-life contexts. This separation into two differentiated domains entails the need for the mathematization of the phenomenon, and for the interpretation of the results obtained using the models constructed. However, the modelling process developed by students is actually documented to be more complex than it appears to be in the modelling cycle diagram, a complexity that may be at the origin of the difficulties for inexperienced modellers (Aymerich \& Albarracín, 2016; Blum \& Borromeo Ferri, 2009).

\section{On Sequences of Modelling Activities}

In recent years, and from different perspectives, there has been some experimentation with the idea of using activity sequences to initiate the students in the learning of modelling. On the one hand, we find the Dual Modelling Cycle Framework (Matsuzaki \& Saeki, 2013) based on the modelling cycle of Blum and Leiss (2007). These authors suggest linking two similar activities to encourage students to develop more elaborate models for representing the studied phenomena and claim that modellers would progress to the second modelling cycle by applying or referring to results from the first one, this way concatenating modelling cycles.

Another perspective was raised by different researchers who work within the paradigm of Models and Modelling. These authors define Model-Eliciting Activities (MEA) as problem-solving activities built upon instructional principles - covered in more detail in Lesh, Hoover, Hole, Kelly, and Post (2000) - with the aim of promoting the students to develop a model of a given situation that may be applied to other similar situations (Doerr \& English, 2003). The students are asked to work in small groups (Zawojewski, Lesh \& English, 2003) and are confronted with a problematic situation that is significant and relevant to them, and for which they should create, expand, and perfect their own mathematical constructions. The results are then conveyed to the rest of the students in the class to trigger a discussion and an exchange of opinions, which may lead to a revision of the process and to the construction of new models. MEA should engage the learners in contrasting strengths and weaknesses of various representations; using language precisely and carefully; and using representations purposefully and productively.

According to Ärlebäck and Doerr (2015a), in a sequence aimed at fostering students to develop their own models, MEA would be the activities to start from, that should be followed by others related to the exploration of the model - Model Exploration Activities (MXA) - and the application of the model - Model Application Activities (MAA). It is necessary to use different types of activities in the classroom, since isolated MEAs may turn out to be insufficient to support students in developing and generalising models that could be used in other contexts. In this sense, it becomes necessary to implement different modelling activities that are related to each other and offer multiple opportunities for the students to explore, apply and test the relevant mathematical constructions for different situations and contexts.

Ärlebäck and Doerr (2015b) insist that special attention should be given to the evolving space of learning promoted by the initial MEA. They suggest that MXAs should contrast the weaknesses and strengths of the model, and the way in which it represents reality, and insist on a precise use of language. Likewise, among other aspects, MAA should call for the use of the model in new contexts and extend the model or connect it with other models. Along these lines Ärlebäck and Doerr (2015b) suggested that, at least from a theoretical standpoint, modelling activity sequences of MEA, MXA and MAA may be directed to making the students connect, coordinate and integrate different mathematical models, and that these processes are crucial to the creation of applicable mathematical models. 


\section{On Estimation and Fermi Problems}

In the following paragraphs we introduce Fermi problems because the problems in our sequence are based on a Fermi problem. Clayton (1996) refers to estimation as the "ability to make assumptions about the value of a distance, costs, sizes, etc. or calculations" (p. 87), which may be part of any field of mathematics. The author points out that estimation is an "ability to conjecture", in the sense that the estimator should have a rough idea about the measure or calculation in order to estimate it. When tackling a problem in real life we may often lack the necessary resources or information to give a precise answer; however, many situations do not require a high level of precision for the answers. In these cases, an estimation of the relevant quantities that characterise the situation may be enough, and an estimate may even be the fastest and most effective answer. Fermin problems are a particular type of situations in which a mathematical model is the base on which to carry out an estimation of a quantity.

Ärlebäck (2009) defines Fermi problems as “open, non-standard problems requiring the students to make assumptions about the problem situation and estimate relevant quantities before engaging in, often, simple calculations (p. 331)". According to Efthimiou and Llewellyn (2007), Fermi problems always appear diffuse in their formulation, giving little concrete information or few relevant aspects on which to focus the resolution. However, with a more detailed analysis, they can be decomposed into simple problems in order to attain the answer to the original question. These characteristics make Fermi problems useful to introduce all types of scientific content to other areas of learning, such as in Physics (Reif \& St. John, 1979; Robinson, 2008), Biology (White, 2004) or Economics (Anderson \& Sherman, 2010).

Fermi problems are used in teaching different scientific disciplines. From the perspective of Mathematical Education, Ärlebäck (2011) states that working with Fermi problems may be useful to introduce modelling to the classrooms for several reasons: 1) they are accessible to students of different educational stages and do not require any type of previous mathematical knowledge; 2) they hold a clear relation to the real world; 3 ) they force the students to define the structure of the relevant information; 4) being open problems that are not associated with any specific knowledge, they require the student to elaborate a resolution strategy; 5) not offering numerical data, the students should estimate several quantities by themselves; and 6) they promote discussion among students. In fact, complex modelling processes have been identified in high school and undergraduate students while solving problems Fermi problems (Ärlebäck, 2009; Czocher, 2016).

Another argument for the introduction of Fermi problems in the classrooms is the possibility to use them as a bridge between mathematics and other school subjects, introducing the students to different interdisciplinary tasks (Sriraman \& Lesh, 2006). They are considered powerful tools to improve critical thinking (Albarracín \& Gorgorió, 2015), in particular when checking the accuracy of computations with different governmental and corporate resources, as Sriraman and Knott (2009) suggest.

In previous studies (Albarracín \& Gorgorió, 2013, 2014), we identified different resolution strategies and models that students used and created when devising the plans to solve Fermi problems that required estimating the number of objects on a plane. Since the strategies and models we identified are part of the framework on which we base the analysis in the present study, we will list them as follows:

- Exhaustive counting: the student suggests counting all the elements of the group of objects one by one.

- External source: the student passes on the responsibility of answering the problem to a third party, who supposedly has the necessary information.

- Concentration measures: the student bases his/her resolution on searching for the value of dividing the number of people or objects over the surface area they occupy, determined by themselves.

- Reference point: the student attempts to determine the total surface area of the place where the people or objects are by determining the number of total elements and dividing it by the surface taken up by a single element, which acts as a reference point - in the sense established by Joram, Gabriele, Bertheau, Gelman and Subrahmanyam (2005) - on measurement processes.

- Grid distribution: the student uses a mental image of the distribution of people and objects on a grid, then estimates the total number found in each area and finally applies the rule of the product to establish the result.

From our interpretation of mathematical models, any model is constituted by integrated concepts and procedures. Therefore, at the theoretical level, two models that do not share procedures and concepts are different models. Therefore, from our theoretical standpoint, the previously listed models are different. Moreover, we observed that the students' discussions rarely involved conceptual aspects but focused on procedural aspects. Therefore, also from the perspective of the students, these models are also essentially different. 


\section{THE STUDY}

\section{Goals}

We studied how a group of 16-year-old students solved a sequence of problems that required estimating large quantities. The sequence of problems was designed to assist students in the creation, exploration, and application of mathematical models.

We wanted to characterise the models that they created when solving the sequence, and to see whether, and how, their strategies and models evolved when dealing with the restrictions imposed by the real-life contexts given by the wording of the problem. We also wanted to see whether the students connected, coordinated and integrated different models towards the construction of a more general one, and how they linked the resolutions of the problems.

\section{Design}

The research presented is a qualitative study of exploratory nature. We worked with a group of secondary students from which we had already collected data in a previous study (Albarracín \& Gorgorió, 2015). The school is located in a city with a population of 200,000, within the metropolitan area of Barcelona, and the students mainly belonged to families with a middle socioeconomic status.

We worked with 22 students aged 16 who were in their last year of compulsory education and had never engaged in solving Fermi problems. We chose this group because their mathematics teacher usually based classroom activities on experimentation. Another reason for our choice was the way the teacher managed students' participation, by setting challenges for the development of ideas, and posing questions to encourage them to evaluate their newly acquired knowledge. Since students usually worked in teams, they were used to sharing their ideas during problem solving sessions.

Large quantity estimation problems are not part of the current Spanish curricula and are not commonly used in class. For this reason, the students of our study were not equipped with any specific method to tackle the problems and had to generate their own strategies and models of the situations that required to estimate large quantities. By setting the problem in a real-life context, the fact of dealing with large quantities did not allow the students to use simplistic approaches to the solution, such as exhaustive object counting.

The sequence of problems presented to the students was designed by the researchers in collaboration with the mathematics teacher. When designing the problem sequence, we introduced nuances that have not been addressed in the previous problems, to avoid problems becoming mere exercises. This way we made sure that each part of the process added new meanings, concepts, and procedures to those previously constructed. For example, the presence of urban furniture that made it impossible to occupy certain spaces, generating restrictions on the problem. In particular, all problems related to real-life questions, and each of them encouraged the students to create complex models. From this perspective, the activities were not mere instructional tasks, but the students had to put concepts previously learned into play to create new mathematical knowledge. In addition, when designing this problem sequence, we took into account the proposals of Lesh et al. (2000) and Lesh (2010) who establish the most relevant aspects of sequences of modelling activities. Following Wessels (2014), we wanted our activities to be complex, contextualised in different real-life situations and far removed from conventional problems associated to welldefined solving procedures.

For our study, we designed a sequence of large quantity estimation problems made up of five Fermi problems. From a strictly mathematical sense, they all have the same request, requiring an estimation of a large quantity of people or objects arranged over a given surface area. The problems in this sequence are the following:

- Problem P1: how many people could we fit in the high school courtyard?

- Problem P2.1: how many people could we fit in the Palau St. Jordi ${ }^{1}$ for a concert?

- Problem P2.2: how many people could we fit in the town hall square of your municipality during a public protest?

- Problem P2.3: how many people could we fit in Plaça Catalunya square - in Barcelona - during a public protest?

- Problem P2.4: how many trees are there in Central Park?

\footnotetext{
${ }^{1}$ Palau St. Jordi is a sports pavilion built for the Barcelona'92 Olympic Games.
} 
The development of the sequence was led by the teacher and was arranged into six consecutive sessions lasting 60 minutes each. We, as researchers, were non-participant observers. In the first session, the students were prompted to estimate the number of people that would fit in the school courtyard and asked to write an individual scheme, in the sense of a plan, to solve it. After that, they were arranged into 6 heterogeneous teams of 3 or 4 students each. Based on the discussion of individual schemes, each group had to come to an agreement on a solving strategy, and define the actions and resources needed to put it into practice.

In the second session, each team actually performed the tasks they had planned during the first session and wrote up reports where they explained the methods used and the solutions reached. During the third session, the reports were completed, and the methods and results were reported to the whole group. The aim of the group discussion was to allow the students to participate with their ideas and experiences by promoting the sharing of knowledge. After sharing the methods and the results for problem P1, during the fourth session, problems P2.1, P2.2, P2.3 and P2.4. were given to the students to be solved. The students approached these problems with the same group arrangement. We present P2 problems to the class all at once but numbered as we have indicated. Although we allow the students to solve them in the order they saw fit, we expect that the dynamics of the classroom will lead them to tackle them in the order suggested by the numbering. Classroom observation confirms our expectation, since they addressed them in the same order in which they were delivered. For P2 problems, students were allowed to use the Internet to obtain any necessary information. The fifth session was used to complete the resolutions of the different problems, and to elaborate a report on the results of the P2 problems. The sixth session was intended to be a conclusive activity in which the students compared the results they had obtained with the information gathered from external sources.

The problems posed constituted a sequence intended for students to create and develop their own models. Problem P1 is a MEA, essentially because this was the first time that these students formally faced a problem that requires the creation of a model. Problem P1 refers to a situation that could be studied empirically at school, and acts as a source of strategies and models. P2 problems were part of the sequence to help the students to question, develop, or reconstruct the models they have created to solve P1, in order to reach a generalizable one. Because of the characteristics of the contexts of P2 problems, the students were not able to actually go to the places referred to in the problem statement. Therefore, to solve them they had to explore whether and how the models created to solve P1 could be adapted to respond to these new situations, this way, contrasting the weaknesses and strengths of the models created. Following Ärlebäck and Doerr (2015b), problems P2.1, P2.2, and P2.3 played the role of MXA within the sequence. P2.4 was different from the previous three; it was no longer about estimating the number of people, but the number of trees in a much larger setting, far removed from the reality of the students. Thus P2.4 acted as MAA (Ärlebäck \& Doerr, 2015b) in the sense that it forced the students to generalize the strategies of the previous problems to use them in another context.

\section{Data}

Since we did not want to interfere in the usual development of the lessons, our data are essentially equivalent to the documents the students handed in to their teacher to get feedback. The dataset collected for this study over the progression of the sequence includes:

- 22 individual schemes or action plans to solve problem P1

- 6 action plans developed in teams to solve problem P1

- 6 reports of the resolution for problem P1, written by each working team

- 6 reports of the resolutions for problems P2.1, P2.2, P2.3 and P2.4 written by each team

We also had access to the information provided by the school on the mathematics curriculum and textbooks they had followed, and on the grades of each student. Additionally, our own field notes from each session allowed us to triangulate the interpretations of the students' output. Furthermore, we asked the teacher to step in when necessary during the interpretation of the reports gathered. Some of the data collected during the experience is detailed below, to illustrate the type of dataset that comprises our primary source of information.

We coded the individual and team action plans, as well as each team's resolution reports. A letter from A to F was assigned to each team, and each student was then named after his/her team's letter plus a number. Next, we present two of the individual action plans, a group action plan and a resolution report, all of them for problem P1.

The individual action plan of student B1 for problem P1 was:

"In order to find out how many people fit in the playground, we have to calculate how big it is to find out its surface area. Once we know the surface area, we can calculate how many people would fit in one square metre and we then multiply it by the number of total square metres in the playground." 


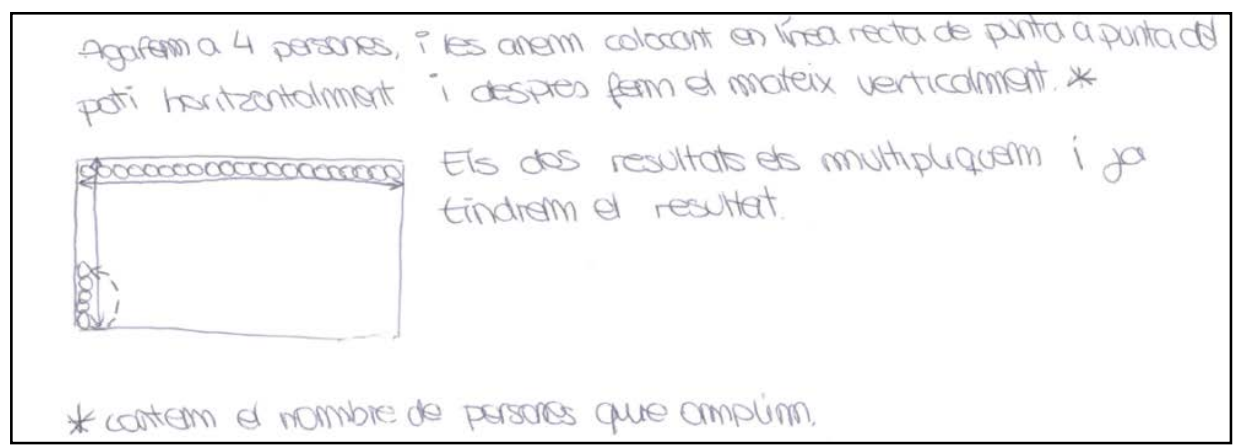

Figure 1. Team C action plan for problem P1

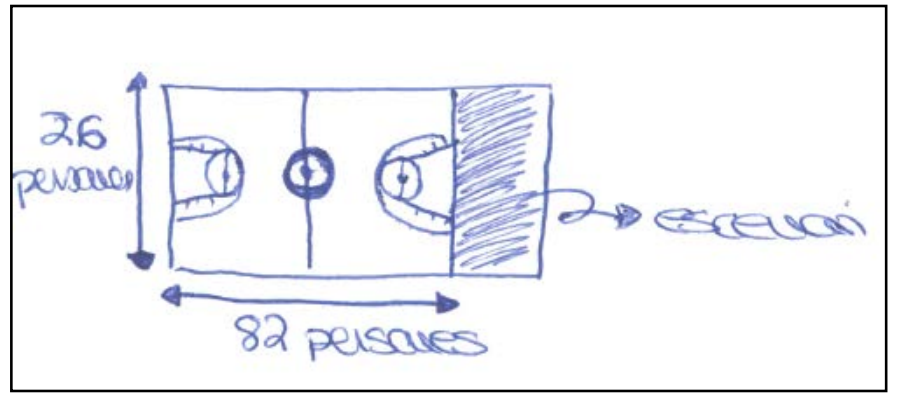

Figure 2. An outline of one of the resolutions for problem P1

Another action plan by a student from the same team, B2, was:

"I would first take the average of the volume occupied by one person and I would divide that by the square metres of the playground, excluding the area of the stage".

Working team B, to which B1 and B2 belong, established the following action plan for problem P1:

1. Using a tape measure, we take the measurements of the playground, where people can stand during a concert.

2. Using the formula 'base $x$ height', we calculate the surface area of the playground.

3. We calculate how many people can fit in a square metre and multiply that by the total square metres of the playground."

Figure 1 shows the action plan for problem P1 of a different working team, team C. These students suggested estimating the amount of people that may fit in the courtyard by counting the number of people that can be arranged along its width and length in rows and columns.

The handwriting in Catalan in Figure 1 reads the following:

"We take 4 people and place them in line from one side to the other of the playground, first horizontally and then vertically (we then count the number of people we can fit in). Both results are multiplied, and this will give us the final result."

Next, we present an outline of the resolution report handed in by team C to problem P1, that follows the action plan presented in the previous paragraph. As shown in Figure 2, students in team C performed their calculations on site and obtained 26 and 82 people as a result for each of the dimensions of the courtyard, hence its capacity turned out to be 2,132 people.

\section{ANALYSIS AND RESULTS}

\section{Criteria for the Analysis}

We proceeded to an interpretative qualitative analysis of the data taking as categories of analysis the typology established in Albarracín and Gorgorió (2014), presented in section 2. Then we identified the action plans devised by the students and observed that the potentially effective strategies were based on the construction of a model 
Table 1. Individual action plans of team $C$

Student C1 Incomplete: Only considers the need to calculate the area occupied by one person.

Gives two different options:

Student C2 Option 1: To perform an exhaustive count of the people.

Option 2: To use the grid distribution method by arranging people in line.

Student $\mathrm{C}_{3}$ To use of the reference point: to measure the surface area (subtracting unusable areas) and divide it by the area

Student C3 taken up by one person (considering a large person).

Student C4 To perform an exhaustive count of people or chairs.

around a specific mathematical concept that would articulate the resolution and included the procedures mathematical or not - necessary to solve the problem.

In our analysis, we firstly characterised the mathematical models generated during the solving process of problem P1, and their evolution from individual action plans to the resolution reports of P1 handed in by the teams. Next, we focussed on the way the students assessed the potentialities and weaknesses of the models created for problem P1 to solve P2 problems, and we characterised the development of their mathematical models that progressively incorporated new concepts and procedures to adjust their solving processes to the conditions of the new problems.

In the following paragraphs, we present the results obtained from analysing the data collected during the development of the sequence, together with a brief argumentation for the categorisation.

\section{Strategies Identified in the First Problem and their Evolution}

In problem P1, students had to estimate the number of people that fit in the courtyard of the school. As example of our analysis, Table 1 shows the individual action plans of the 4 members of team $C$, which allowed them to create a joint action plan.

The joint resolution presented by group $C$, that was described when exemplifying the data and was shown in Figure 2, is based on one of student's - C2 - action plan and is "To use the grid distribution by arranging people in line to fill the width and length of the playground and then multiply the two values". To measure the number of people that fit along the length and width of the courtyard, the 4 students stood in line and advanced alternately while counting the number of people needed to reach the end, leaving a space to place a hypothetical stage. Finally, they multiplied the number of people that fit along each dimension of the rectangular courtyard.

The mathematical model used by these students is conceptually based on the distribution of people on a grid, and the rule of the product is the procedure to obtain the result, once the numbers to be multiplied have been determined experimentally. Considering the evolution from the initial schemes up to the resolution delivered, we observe that the team adopted a model created by one of its members - grid distribution -, and added elements contributed by the other members of the team - e.g. considering the space for the stage. The actual implementation of the action plan forced the students to search for a practical way to carry out the counting, since they were not enough to fill both dimensions of the courtyard. If we look at their resolution as a modelling process, we observe that working on site prompts the students to add procedural aspects to the constructed model to complement the conceptual aspects decided while they were in the classroom.

According to the evidences in the resolution reports of each team - from A to F -, in Table 2 we summarise the strategies appearing in the individual action plans, the team joint action plan, and the strategy actually used when solving the problem. Thus, the table shows the evolution of models and strategies from individual action plans to final resolution.

In Table 2 we see that three of the teams (B, D, and E) used a strategy based on the idea of population density. The students measured the length and width of the courtyard to calculate its surface area, then experimentally obtained a value of population density - students per square metre -, and they multiplied it by the total surface area calculated for the courtyard in square metres.

Group C, whose resolution was presented as an example at the beginning of this section, based its resolution on the grid distribution model. Groups A and F handed in a resolution based on the iteration of a reference point. The students measured the length and width of the courtyard, calculated its total surface area, and carried out small experiments to determine the amount of surface area one person would take during a concert, as suggested by the problem's context. They considered this value as a unit that could be iteratively applied over the total, for which they divided the total area of the courtyard by the surface occupied by one person. 
Table 2. Strategies identified in the different moments of the solving process of problem P1

\begin{tabular}{|c|c|c|c|c|}
\hline \multicolumn{3}{|c|}{ Team Student Individual Proposal } & \multirow{4}{*}{$\begin{array}{l}\text { Team Proposal } \\
\text { To reduce the problem to a } \\
\text { smaller one (a specific area of } \\
\text { the courtyard) and apply the } \\
\text { proportionality between the } \\
\text { surface of that part and the } \\
\text { total }\end{array}$} & \multirow{4}{*}{$\begin{array}{l}\text { Final Resolution } \\
\text { Reference point: divide the } \\
\text { total surface area of the } \\
\text { courtyard by the surface } \\
\text { occupied by one person }\end{array}$} \\
\hline \multirow{3}{*}{ A } & $\mathrm{A} 1$ & $\begin{array}{l}\text { Reference point (space occupied by one } \\
\text { person) }\end{array}$ & & \\
\hline & $\mathrm{A} 2$ & Population density (people per square metre) & & \\
\hline & A3 & $\begin{array}{l}\text { Population density } \\
\text { Suggests subtracting unusable areas }\end{array}$ & & \\
\hline \multirow{3}{*}{ B } & B1 & Population density & \multirow{3}{*}{$\begin{array}{l}\text { Reference point: divide the } \\
\text { total surface area of the } \\
\text { courtyard by the surface area } \\
\text { occupied by one person }\end{array}$} & \multirow{3}{*}{$\begin{array}{l}\text { Population density: Multiply } \\
\text { the surface area of the } \\
\text { courtyard in square metres by } \\
\text { the number of people that take } \\
\text { up a square metre }\end{array}$} \\
\hline & B2 & Reference point & & \\
\hline & B3 & Population density & & \\
\hline \multirow{4}{*}{ C } & $\mathrm{C} 1$ & $\begin{array}{l}\text { Incomplete, only considers the space occupied } \\
\text { by one person }\end{array}$ & \multirow{4}{*}{$\begin{array}{l}\text { Grid distribution: Counting the } \\
\text { number of people that can fit } \\
\text { in the courtyard in rows and } \\
\text { columns and multiply both } \\
\text { values }\end{array}$} & \multirow{4}{*}{$\begin{array}{l}\text { Grid distribution: Counting the } \\
\text { number of people that can fit } \\
\text { in the courtyard in rows and } \\
\text { columns and multiply both } \\
\text { values. } \\
\text { They reserve an area to put the } \\
\text { stage (concert). }\end{array}$} \\
\hline & $\mathrm{C} 2$ & $\begin{array}{l}\text { Op 1: Exhaustive counting } \\
\text { Op 2: Grid distribution (people in rows and } \\
\text { columns) }\end{array}$ & & \\
\hline & $\mathrm{C} 3$ & ce point & & \\
\hline & C4 & ounting of people & & \\
\hline \multirow{3}{*}{ D } & D1 & Population density & \multirow{3}{*}{$\begin{array}{l}\text { Population density: Multiply } \\
\text { the surface area of the } \\
\text { courtyard in square metres by } \\
\text { the number of people that can } \\
\text { fit in a square metre. } \\
\text { They reserved an area to put } \\
\text { the stage (concert). }\end{array}$} & \multirow{3}{*}{$\begin{array}{l}\text { Population density: Multiply } \\
\text { the surface area of the } \\
\text { courtyard in square metres by } \\
\text { the number of people that can } \\
\text { fit in a square metre. } \\
\text { They reserved an area to put } \\
\text { the stage (concert). }\end{array}$} \\
\hline & D2 & Exhaustive counting of people & & \\
\hline & D3 & Population density & & \\
\hline \multirow{4}{*}{$E$} & E1 & Population density & \multirow{4}{*}{$\begin{array}{l}\text { Population density: Multiply } \\
\text { the surface area of the } \\
\text { courtyard in square metres by } \\
\text { the number of people that can } \\
\text { fit in a square metre. }\end{array}$} & \multirow{4}{*}{$\begin{array}{l}\text { Population density: Multiply } \\
\text { the surface area of the } \\
\text { courtyard in square metres by } \\
\text { the number of people that can } \\
\text { fit in a square metre. }\end{array}$} \\
\hline & E2 & Reference point & & \\
\hline & E3 & $\begin{array}{l}\text { Reference point } \\
\text { They mistake surface and volume }\end{array}$ & & \\
\hline & E4 & $\begin{array}{l}\text { Incomplete: suggests using population density } \\
\text { without determining the total surface area }\end{array}$ & & \\
\hline \multirow{5}{*}{ B } & F1 & & \multirow{5}{*}{$\begin{array}{l}\text { Reference point: divide the } \\
\text { total surface area of the } \\
\text { courtyard by the surface area } \\
\text { occupied by one person }\end{array}$} & \multirow{5}{*}{$\begin{array}{l}\text { Reference point: divide the } \\
\text { total surface area of the } \\
\text { courtyard by the surface area } \\
\text { occupied by one person }\end{array}$} \\
\hline & $\mathrm{FT}$ & Suggests subtracting unusable space & & \\
\hline & F2 & Reference point & & \\
\hline & F3 & $\begin{array}{l}\text { Incomplete: suggests measuring the surface } \\
\text { area }\end{array}$ & & \\
\hline & F4 & Population density & & \\
\hline
\end{tabular}

It is interesting to note that group A started from an action plan based on reducing the problem to a smaller one and then applying proportionality. However, they soon realized that, in practice, they would need to be a larger team and changed their scheme, shifting their initial plan into a reference point strategy. Reviewing the curriculum that the students had followed, and the examinations they had had, we observe that they had studied proportionality through solving missing value and ratio problems. They had also had access to the idea of linear function, however, they never did so from the perspective of having to identify relations of proportionality. Somehow, all the exercises and problems of proportionality, had been presented to them under the heading proportionality, with which, they had never had to distinguish whether a situation was proportional or not.

On the whole, we saw that the strategies identified were based on three concepts that supported three different models - grid distribution, population density and iteration of a reference point - allowing the students to create a simplified representation of the studied reality based on creating more attainable sub-problems. Some of these subproblems included different procedures such as finding the surface area of the courtyard, determining the number of people that fit in a square metre, or calculating the number of people in a row in the courtyard. These subproblems were determined by the conceptual basis of the chosen model and could be solved more easily than the original ones.

In relation to the evolution from individual action plans to the implementation of the solving process, in general, we observed that to establish an action plan, the teams used the ideas suggested by one of their members and then added details contributed by other members. In addition, when actually carrying out their joint action plan, the teams identified the elements their action plan was lacking and modified it on site. This change, in some cases, was 
related to the restrictions of the context of the problem. Team C's resolution is an example of this type of adjustment, since they changed the initial plan when realising they needed to leave out a space for the concert stage.

Moreover, we noticed some changes in the development of the solving processes that were more significant, since they consisted of shifting between the strategy of the initial plan, and the strategy that was actually carried out in the resolution. In these cases, the strategy defined by the concept that supported the model involved procedures that could finally not be activated. We observed that students did not question the model they were using until they encountered a procedure that could not be carried out, usually as a consequence of the characteristics of the context. We interpreted that they did not include the validation of models as part of their activity. Again, we see that the change of models did not arise from a discussion about the concepts that sustain the models but from the limitations of the procedures. This was the case of group A that changed their strategy on encountering obstacles while defining an area of the courtyard. This team transformed their initial plan that involved splitting the problem into sub-problems and applying proportionality, to a resolution based on the strategy of the reference point.

\section{Changes of Models and Adjustments when Progressing in the Sequence}

In this section, we focus on the solving process of problems P2.1, P2.2, P2.3 and P2.4 that were presented to the students after a joint discussion on the methods used and the results obtained for problem P1. This new set of problems brought about new challenges. On the one hand, the students had to see whether the models discussed and agreed upon after solving problem P1 - a MEA - could still be used to solve P2 problems and find a way to deal with the restrictions imposed by the new contexts in the formulations of the problems. On the other hand, the students were not able to solve the problems empirically given that the locations mentioned in the statement were not within their reach. To overcome this setback, the students decided to find the information they required on the internet. Even if the students were allowed to tackle them in the order they saw fit, we observed that, as we expected, they solved them in the order proposed - P1, P2.1, P2.2, P2.3, leaving P2.4 for the end of the sequence.

From the analysis of the written reports, we observed that all the groups solve the MXA - P2.1, P2.2 and P2.3 using a model based on the idea of population density, incorporating new details when moving from one activity to the next one. We also found a model based on the idea of population density in the resolutions of problem P2.4 delivered by four of the six groups. In the other two we identified the model based on the iteration of a reference point. Being P2.4 a MAA, there was a change of context that introduced substantive restrictions in the procedures, which lead to change the conceptual strategy.

A significant finding is that the population density was the most adaptable one. They only used the iteration of a reference point in two of the problem P2.4 reports, where the space occupied by a tree was established as the unit of the surface area to estimate the total number of trees in Central Park. We knew from our field notes that both groups regarded the density of trees expressed in units per square metre as a difficult number to deal with. Since "a tree can occupy a considerably bigger area than a square metre" they had to deal with positive numbers smaller than one. Having to handle these numbers lead them to abandon the population density model and return to one of those that had been discussed at the end of P1.

We also observed that the students introduced new elements that enriched their models with respect to the resolutions of problem P1. These modifications were related to the particularities of the contexts established by the wording of the problems, and a consequence of a better interpretation of the real-life context, that is, of a better mathematization of the given situation:

- Some areas could not be used. When devising the action plans for the problems set in urban areas and in Central Park, the students noticed that some spaces could not be used because of street furniture and road traffic signals. They overcame this difficulty by using an aerial image on Google Maps, delimiting the areas, and using the tool provided to measure the lengths they to calculate the different surface areas.

- There are areas with different population densities. When approaching the problem involving Palau St. Jordi they noticed that there were two spaces that were clearly different, and that would have different population densities depending on the way people filled them. Then, since they could not get an image of the inside of the building, they approximated the surface of each space by reasoned estimations.

- The density of people or objects was not always the same. The students found that the density of people in a concert or a public protest, and the density of trees was not always the same. When estimating the density of trees in Central Park the students searched for information on sizes of the trees depending on species and age. They also considered the density of people on the grandstand to be different from that of the concert floor and would likewise be different from the density of people in a public protest. 
Table 3. Evolution of the strategies

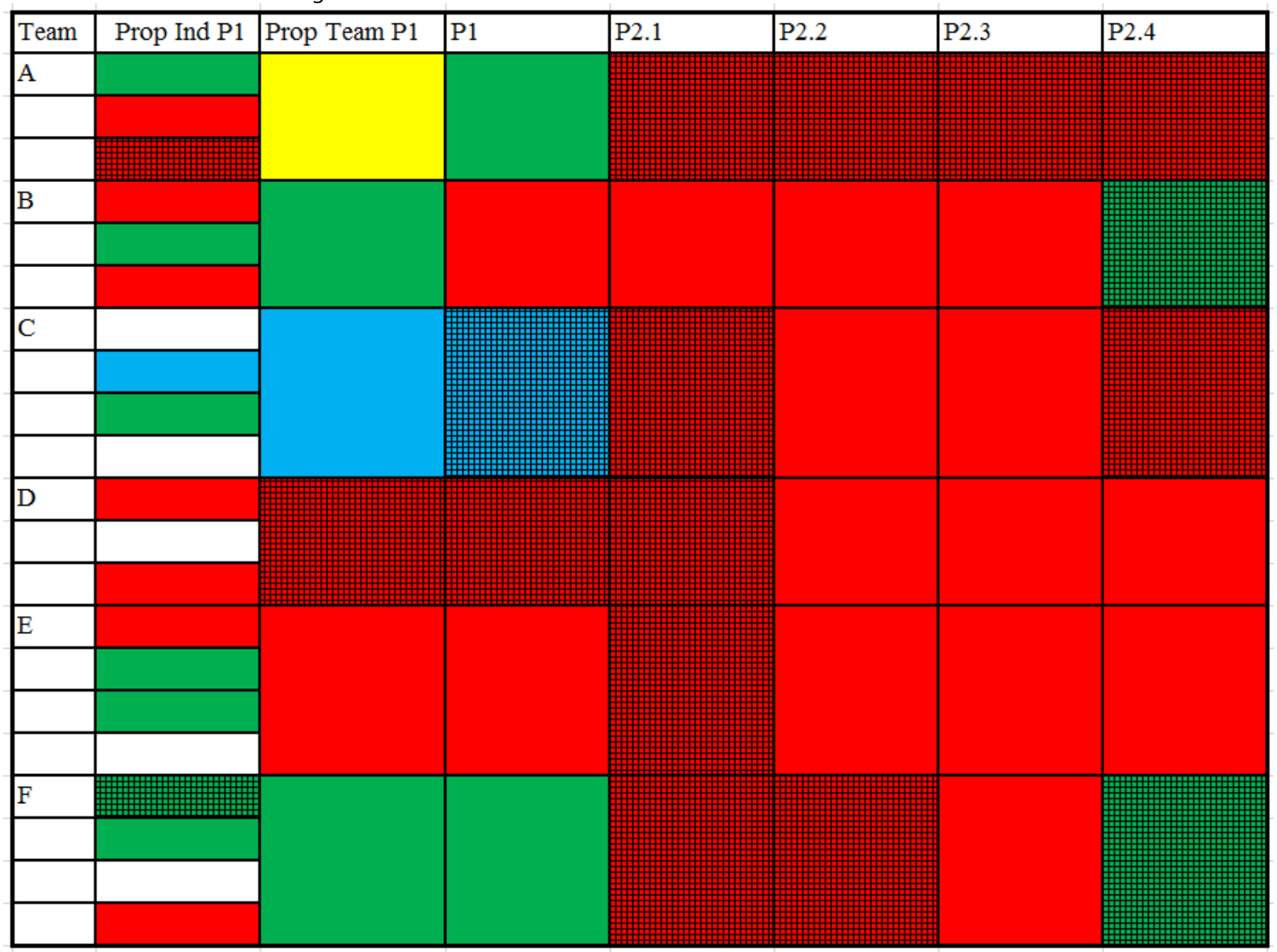

\section{Interpreting and Validating: Population Density as an Adaptable Model}

In order to visualise the development of strategies throughout the sequence of problems, Table 3 summarises the analysis of resolution reports handed in by the different teams for the different problems. The first three columns refer to the solving process of problem P1 - individual action plan, team action plan, and final resolution - and the next four correspond to the solving process of P2 problems. This table shows the strategy used following a colour coding (Green $=$ Reference point, Red $=$ Population density, Blue $=$ Grid distribution, Yellow $=$ Reduction to a smaller problem, White = Incomplete or exhaustive counting). At the same time, both the plans and resolutions that include specific adaptations for the chosen strategy - as commented in the previous section - have been marked with cross-lined shading.

We observe that, after the joint discussion on the resolution of problem P1, the predominant strategy was based on population density. Only two groups used the strategy of the iteration of a reference point because of the procedural difficulties involved in working with numbers between zero and one. In addition, the table shows that they increasingly introduced adjustments to the population density model because of a more elaborated interpretation of the real-life context. Throughout the sequence, we have seen that the students progressively abandoned some poor strategies present in some of the individual action plans to embrace strategies adaptable to a greater number of scenarios, until reaching a model that was not only useful to solve a particular problem, but that could be applied to all the given situations. Students' strategies converged towards applying the population density model which students recognized to be adaptable enough to incorporate adjustments to fit in the various restrictions imposed by the context.

As part of the usual routine, once the sequence of problems was solved, the activity ended with a discussion on validity of the results. The students used information from different sources on the web, such as Wikipedia and online newspapers, to compare with their results. In this way they were not only able to establish clear connections to the reality studied but learned to value their own strategies. It is worth mentioning the case of the estimation of the number of trees in Central Park. On completion of the activity, after looking for and contrasting information in several sources, the students found strikingly disparate values, which triggered a discussion. Some of the sources 
offered values close to those obtained by them, but others greatly magnified the number of trees. Finally, a student accessed a website in English and realized that the differences may had been due to an incorrect translation of the word 'shrub', which confirms that other websites provided wrong figures. This final validation process strengthened the students' confidence in their learning and provided them with resources to have a critical point on information provided by the media (Albarracín \& Gorgorió, 2015).

\section{CONCLUSIONS}

In this paper we report on how a group of 16 years-old students dealt with a sequence of large quantity estimation problems designed to promote different learning outcomes, including the students' creation and use of mathematical models. It is a feature of our study that participants had no previous experience with modelling, and that the class was used to work under a certain organization. The problems of the sequence were initially situated in contexts close to their own reality that become progressively more distant. This distance gave rise to new difficulties, requiring the students to adapt, or change their models to adjust them to the problem's context-specific characteristics. The first problem allowed the students to devise a solving strategy based on a first mathematical model to study a situation that was close to them. The discussion after the first problem was solved, together with the second set of problems that required tackling situations that were not within direct reach, lead the students to question the weaknesses and strengths of the models initially created. The conditions imposed by the real context, such as the consideration of regions with different degrees of occupation, the existence of closed or occupied zones by pre-existing elements, or possible movements of people in a protest, have an impact on how mathematics can be called to represent the situation. Then, the MXAs caused the students to deal with situations farther from their direct experience and more demanding from the point of view of their conceptualization, this way encouraging students to progressively refining their initial model. Therefore, the first problem acted as a generator and the following acted as exploration and application activities (Doerr and English, 2003).

Since all models are constituted by concepts and procedures, based on the results of Albarracín and Gorgorió (2014), we characterized the models generated by the students according to the concepts underlying the solving strategies they develop. In this way we observed that the concepts generated throughout the sequence supported three different models: grid distribution, iteration of a unit, and population density. It is important to note that the same kind of situation, apparently simple in its statement, could generate a great variety of structurally different methods to solve it, showing that students brought to the activity different background knowledge or points of view. These three models already appeared at the beginning of the process, when the students devised their action plans. However, as they moved through the sequence we observed that students progressively abandoned the poorer strategies of the initial individual schemes to adopt more adjustable strategies, finally opting for the model based on the population density model. From the point of view of an expert mathematician, the iteration of the unit, the grid distribution and the idea of density could be considered variations of the same model. However, at the beginning, the students had not established the connections between these ideas. This was precisely the purpose of the MXA.

Throughout the sequence we saw how the students adapted the models to each situation, either shifting strategies or adjusting the procedures. Students shifted models, that is, changed the concepts that supported the model, when the strategies that defined them involved procedures that could not be activated. Students did not question the model they were using until they encountered a procedure that could not be carried out, as a consequence of the characteristics of the context, or at the time ideas were shared in the joint discussion and new models appeared that could be used. We saw that the change of models did not arise from a discussion about the concepts that sustained them but from the limitations of the procedures. It is worth to notice that, although any model is an integration of concepts and procedures, in the 360 minutes of classroom activity we did not obtain any evidence of students discussing conceptual strategies, not even when they decided to shift models when faced with procedural obstacles or limitations. The students discussed whether changing a procedure would contribute to overcome the limitations of their proposals. We didn't see any discussion about why one procedure didn't work, or why another would be more efficient. The students were talking about how but not about why.

Students adjusted the models, introducing elements that did not substantially change the strategy, because they were based on the same concept, but that incorporated nuances resulting from a mathematization of the situation under study. They created models based on knowledge they had previously learned but used it in ways they had never specifically studied. This is what happened, for example, when they assigned different densities to different zones, or when they broke a problem into smaller parts that end up being subproblems in which they could apply proportionality. Therefore, the sequence of activities is not only a good educational tool to introduce modelling, but also generates other learning outcomes.

Although it is clearly a good learning sequence, we have no evidence that the students fully integrated the models as suggested by Arlebäck and Doerr (2015b) from a theoretical perspective. We observed that, in several cases, they adapted a model by connecting and coordinating different features to mould it to the new problem but, 
in others, they substituted one model by another. We observed that the students ended up opting for the model based on population density, since they perceived it to be the most efficient one. We therefore concluded that the students had generated a set of coordinated knowledge they could use with versatility by integrating elements of the different models constructed, and identifying which elements rendered them useful in each situation. To have evidence that students end up integrating models, as Arlebäck and Doerr (2015b) suggest, another type of research would be necessary, likely with students with experience in modelling, facing more complex activities, and where the data were collected through interviews after the development of the activities.

Our results align with what Matsuzaki and Saeki (2013) put forward that linking two similar activities would encourage students to develop more elaborate models for representing the studied phenomena. However, our results question the concatenation of modelling cycles that they propose. In our study, those students who had created a model for the first problem that allowed them to continue solving the new ones did not generate a new cycle of modelling, but rather took up the previous one. This is evident in the fact that they dispense with validation processes until ideas are shared in the discussion, or a new problem is addressed. In this sense, the results of our study show that in order to design more effective modelling activities it would be worthwhile to investigate what makes students rethink the mathematical models generated. Our study seems to imply that what promotes the rethinking of models is the inability to use them in new situations. Discussions during the sharing provide new ideas that can facilitate model change, unblocking the solving process.

In our study, all students had participated, actively or not, in the discussion where they shared the advantages and limitations of the models generated for the first problem. This is the explanation why students who generated a model for the first problem, even if it didn't allow them to solve the new ones, did not initiate a new modelling cycle either. In fact, they adopted the model they considered most appropriate among the discussed, co-ordinating it with the elements they had built that were still valid. Therefore, even though students had applied or referred to results from the first cycle, we have no evidence of concatenation of modelling cycles. Possibly the most significant reason for this discrepancy between our results and Matsuzaki and Saeki's (2013) proposal is the organization of work in the class. Addressing the second group of problems only after students had shared not only the models they had developed, but also their weaknesses and potentialities, is key in how they link the resolutions of the problems along the sequence.

In some way, the organization of work in the classroom allowed to overcome, at least partially, the difficulties in unexperienced modelers documented by Blum and Borromeo Ferri (2009). This classroom dynamic allowed students to assess what proposals were more suited to each situation, and were able to compare a wide range of possibilities. During the discussions it became apparent that the most adaptable was by far the model based on population density, since it could easily be adapted to different problems. Therefore, even though the approach to the sequence was open and allowed students to freely develop their own models, the nature of the problems lead students towards the development of a specific model.

As a general conclusion we claim that our study confirms that Fermi's problems constitute a type of activity that promotes the creation of mathematical models, so they are potentially useful to introduce modelling in Secondary Education. In addition, the design of the sequence of problems, together with the introduction of joint discussions, encourages students to reconsider the mathematical models generated. This way orienting their work towards the development of a model that meets the characteristics necessary to address various types of problems that require to estimate large quantities of objects on a surface. Thus, the sequence of problems that we have designed allows an open work that, at the same time, is directed towards the creation of the model of population density, and therefore it is possible to anticipate the knowledge that the students will put into action. Therefore, the sequence of problems could be chosen to work in class by even the most reluctant teachers to work with open activities.

\section{ACKNOWLEDGEMENT}

Research supported by the projects EDU2017-82427-R (Ministerio de Economía, Industria y Competitividad, Spain) and 2017 SGR 497 (AGAUR, Generalitat de Catalunya).

\section{REFERENCES}

Albarracín, L., \& Gorgorió, N. (2013). Problemas de estimación de grandes cantidades: modelización e influencia del contexto. Revista Latinoamericana de Investigación en Matemática Educativa, 16(3), 289-315. https:// doi.org/10.12802/relime.13.1631

Albarracín, L., \& Gorgorió, N. (2014). Devising a plan to solve Fermi problems involving large numbers. Educational Studies in Mathematics, 86(1), 79-96. https:/ / doi.org/10.1007/s10649-013-9528-9 
Albarracín, L., \& Gorgorió, N. (2015). On the Role of Inconceivable Magnitude Estimation Problems to Improve Critical Thinking. In U. Gellert, J. Giménez, C. Hahn and S. Kafoussi (eds.), Educational Paths to Mathematics (pp. 263-277). Dordrecht: Springer International Publishing.

Anderson, P. M., \& Sherman, C. A. (2010). Applying the Fermi estimation technique to business problems. The Journal of Applied Business and Economics, 10(5), 33.

Ärlebäck, J. B., \& Doerr, H. M. (2015a). Moving Beyond a Single Modelling Activity. In G. Stillman, W. Blum \& M. S. Biembengut (Eds.) Mathematical Modelling in Education Research and Practice (pp. 293-303). Dordrecht: Springer International Publishing.

Ärlebäck, J. B., \& Doerr, H. M. (2015b). At the core of modelling: Connecting, coordinating and integrating models. In K. Krainer \& N. Vondrová (Eds.), Proceedings of the 9th Congress of the European Society for Research in Mathematics Education (pp. 802-808). Prague, Czech Republic: Charles University in Prague, Faculty of Education and ERME.

Ärlebäck, J. B. (2009). On the use of realistic Fermi problems for introducing mathematical modelling in school. The Montana Mathematics Enthusiast, 6(3), 331-364. https:/ / doi.org/10.1007/978-1-4419-0561-1_52

Ärlebäck, J. B. (2011). Exploring the solving process of groups solving realistic Fermi problem from the perspective of the anthropological theory of didactics. In M. Pytlak, E. Swoboda \& T. Rowland (Eds.) Proceedings of the Seventh Congress of the European Society for Research in Mathematics Education (CERME7) (pp. 1010-1019). Rzeszów: University of Rzeszów, Poland.

Aymerich, À., \& Albarracín, L. (2016). Complejidad en el proceso de modelización de una tarea estadística. Modelling in Science Education and Learning, 9(1), 5-24. https:/ / doi.org/10.4995/msel.2016.4121

Blum, W. \& Leiss, D. (2007). How do students' and teachers deal with modelling problems? In C. Haines, P. Galbraith, W. Blum \& S. Khan (Eds.), Mathematical Modelling: Education, Engineering and Economics. (pp. 222231). Chichester, UK: Horwood Publishing.

Blum, W., \& Borromeo Ferri, R. B. (2009). Mathematical modelling: Can it be taught and learnt? Journal of Mathematical Modelling and Application, 1(1), 45-58. https:/ / doi.org/10.1007/978-94-007-0910-2_3

Borromeo Ferri, R. (2006). Theoretical and empirical differentiations of phases in the modelling process. ZDM, 38(2), 86-95. https:// doi.org/10.1007/BF02655883

Clayton, J. (1996). A criterion for estimation tasks. International Journal of Mathematical Education in Science and Technology, 27(1), 87-102.

Czocher, J. A. (2016). Introducing Modeling Transition Diagrams as a Tool to Connect Mathematical Modeling to Mathematical Thinking. Mathematical Thinking and Learning, 18(2), 77-106. https:/ / doi.org/10.1080/10986065.2016.1148530

Doerr, H. M., \& English, L. D. (2003). A modeling perspective on students' mathematical reasoning about data. Journal for Research in Mathematics Education, 34(2) 110-136. https:/ / doi.org/10.2307/30034902

Efthimiou, C. J., \& Llewellyn, R. A. (2007). Cinema, Fermi problems and general education. Physics education, 42(3), 253. https:// doi.org/10.1088/0031-9120/42/3/003

Joram, E., Gabriele, A. J., Bertheau, M., Gelman, R., \& Subrahmanyam, K. (2005). Children's use of the reference point strategy for measurement estimation. Journal for Research in Mathematics Education, 36(1), 4-23.

Lesh, R. (2010). Tools, researchable issues and conjectures for investigating what it means to understand statistics (or other topics) meaningfully. Journal of Mathematical Modelling and Application, 1(2), 16-48. https://doi.org/10.2307/30034918.

Lesh, R., \& Harel, G. (2003). Problem solving, modeling, and local conceptual development. Mathematical Thinking and Learning, 5(2), 157-189. https:/ / doi.org/10.1080/10986065.2003.9679998

Lesh, R., Hoover, M., Hole, B., Kelly, A., \& Post, T. (2000). Principles for developing thought-revealing activities for students and teachers. In A. E. Kelly \& R. A. Lesh (eds.) Handbook of research design in mathematics and science education, (pp. 591-645). London, UK: Routledge

Matsuzaki, A., \& Saeki, A. (2013). Evidence of a dual modelling cycle: Through a teaching practice example for preservice teachers. In G. A. Stillman, G. Kaiser, W. Blum, \& J. P. Brown (Eds.), Teaching mathematical modelling: Connecting to research and practice (pp. 195-205). Dordrecht: Springer International Publishing.

Perrenet, J., \& Zwaneveld, B. (2012). The many faces of the mathematical modeling cycle. Journal of Mathematical Modelling and Application, 1(6), 3-21.

Pollak, H. O. (1979). The interaction between mathematics and other school subjects. In UNESCO (eds.) New Trends in Mathematics Teaching IV, (pp. 232-248). Paris: UNESCO. 
Reif, F., \& St. John, M. (1979). Teaching physicists' thinking skills in the laboratory. American Journal of Physics, 47(11), 950-957. https:/ / doi.org/10.1119/1.11618

Robinson, A. W. (2008). Don't just stand there-teach Fermi problems! Physics Education, 43(1), 83.

Sriraman, B., \& Knott, L. (2009). The mathematics of estimation: Possibilities for interdisciplinary pedagogy and social consciousness. Interchange, 40(2), 205-223. https:/ / doi.org/10.1007/s10780-009-9090-7

Sriraman, B., \& Lesh, R. (2006). Modeling conceptions revisited. ZDM The International Journal on Mathematics Education, 38(3), 247-254. https:/ / doi.org/10.1007/BF02652808

Wessels, H. M. (2014). Levels of mathematical creativity in model-eliciting activities. Journal of Mathematical Modelling and Application, 1(9), 22-40.

White, H. B. (2004). Math literacy. Biochemistry and Molecular Biology Education, 32(6), $410-411$. https:/ / doi.org/10.1002/bmb.2004.494032060415

Zawojewski, J., Lesh, R., \& English, L. D. (2003). A models and modeling perspective on the role of small group learning activities. In R. Lesh \& H. M. Doerr (Eds.), Beyond constructivism: Models and modeling perspectives on mathematics teaching, learning, and problem solving. Mahwah, NJ: Lawrence Erlbaum Associates, Inc.

\section{http://www.ejmste.com}

